\begin{tabular}{|c|l|}
\hline Title & A irflow limitation and airway dimensions in chronic obstructive pulmonary disease. \\
\hline Author(s) & $\begin{array}{l}\text { Hasegawa, Masaru; Nasuhara, Y asuy uki; Onodera, Y uya; Makita, Hironi; Nagai, Katsura; Fuke, Satoshi; Ito, Y oko; } \\
\text { Betsuyaku, Tomoko; Nishimura, Masaharu }\end{array}$ \\
\hline Citation & $\begin{array}{l}\text { A merican Journal of Respiratory and Critical Care Medicine, 173(12), 1309-1315 } \\
\text { https://doi.org/10.1164/fccm.200601-0370C }\end{array}$ \\
\hline Issue Date & 2006-06-15 \\
\hline Doc URL & http://hdl.handle.net/2115/17093 \\
\hline Type & article \\
\hline File Information & A JR\&CCM173-12.pdf \\
\hline
\end{tabular}

Instructions for use 


\title{
Airflow Limitation and Airway Dimensions in Chronic Obstructive Pulmonary Disease
}

\author{
Masaru Hasegawa, Yasuyuki Nasuhara, Yuya Onodera, Hironi Makita, Katsura Nagai, Satoshi Fuke, Yoko Ito, \\ Tomoko Betsuyaku, and Masaharu Nishimura \\ First Department of Medicine and Department of Radiology, Hokkaido University School of Medicine, Sapporo, Japan
}

\begin{abstract}
Rationale: Chronic obstructive pulmonary disease (COPD) is characterized by airflow limitation caused by emphysema and/or airway narrowing. Computed tomography has been widely used to assess emphysema severity, but less attention has been paid to the assessment of airway disease using computed tomography.

Objectives: To obtain longitudinal images and accurately analyze short axis images of airways with an inner diameter $\geqslant 2 \mathbf{~ m m}$ located anywhere in the lung with new software for measuring airway dimensions using curved multiplanar reconstruction.

Methods: In 52 patients with clinically stable COPD (stage I, 14; stage II, 22; stage III, 14; stage IV, 2), we used the software to analyze the relationship of the airflow limitation index $\left(\mathrm{FEV}_{1}, \%\right.$ predicted) with the airway dimensions from the third to the sixth generations of the apical bronchus (B1) of the right upper lobe and the anterior basal bronchus (B8) of the right lower lobe. Measurements and Main Results: Airway luminal area (Ai) and wall area percent (WA\%) were significantly correlated with FEV $_{1}(\%$ predicted). More importantly, the correlation coefficients $(r)$ improved as the airways became smaller in size from the third (segmental) to sixth generations in both bronchi (Ai: $r=0.26,0.37$, 0.58 , and 0.64 for $\mathrm{B} 1 ; r=0.60,0.65,0.63$, and 0.73 for $\mathrm{B} 8$ ).

Conclusions: We are the first to use three-dimensional computed tomography to demonstrate that airflow limitation in COPD is more closely related to the dimensions of the distal (small) airways than proximal (large) airways.
\end{abstract}

Keywords: airway luminal area; airway wall; computed tomography; multiplanar reconstruction; small airway

Chronic obstructive pulmonary disease (COPD) is a disease characterized by airflow limitation that is not fully reversible and consists of small airway disease (obstructive bronchiolitis) and parenchymal destruction (emphysema), the relative contributions of which vary among patients (1). Thin-section computed tomography (CT) has been used to quantify emphysema by detecting low attenuation areas (LAA), and the role of CT in diagnosing emphysema, including subclinical emphysema $(2,3)$, has been well established (4-9). However, airflow limitation evaluated by forced expiratory volume in $1 \mathrm{~s}\left(\mathrm{FEV}_{1}\right)$ does not necessarily have a good correlation with the severity of emphysema as evaluated by CT (10), because small airway disease

(Received in original form January 9, 2006; accepted in final form March 21, 2006) Supported by Ministry of Education, Science, Culture and Sports of Japan grant $12,877,091$ (to (M.N.) and by a research grant from Nippon Boehringer Ingelheim Co., Ltd, and Pfizer Japan, Inc.

Correspondence and requests for reprints should be addressed to Masaharu Nishimura, M.D., First Department of Medicine, Hokkaido University School of Medicine, N-15 W-7 Kita-ku, Sapporo 060-8638, Japan. E-mail: ma-nishi@med. hokudai.ac.jp

This article has an online supplement, which is accessible from this issue's table of contents at www.atsjournals.org

Am J Respir Crit Care Med Vol 173. pp 1309-1315, 2006

Originally Published in Press as DOI: 10.1164/rccm.200601-0370C on March 23, 2006

Internet address: www.atsjournals.org appears to contribute more significantly to the airflow limitation in COPD $(1,11-14)$.

Recent progress in CT technology has made it possible to detect and quantify airway abnormalities (15-17). Indeed, to improve the diagnostic yield for peripheral small nodules we have been using virtual bronchoscopy, a novel CT-based technique that allows a noninvasive intraluminal evaluation of the airways up to about the eighth generation (18-20). Theoretically, thin-section CT can depict the dimensions of airways as small as approximately $1-2 \mathrm{~mm}$ in inner diameter. Therefore, it has been suggested that CT can be used to evaluate airway dimensions in a variety of diseases (21-26). However, there have been only a few studies that have focused on measuring the airway dimensions in patients with COPD (27-30). Nakano and colleagues were the first to report that wall thickening in the apical bronchus of the right upper lobe had a significant correlation with $\mathrm{FEV}_{1}$ (\% predicted) in patients with COPD (27). By comparing the CT findings of large airways with the dimensions of small airways that were measured using histologic samples, they subsequently found that the airway dimensions of large bronchi could provide a rough estimate of small airway disease (28).

However, previous reports have, unfortunately, had some inherent technological problems with respect to the measurement of airway dimensions. First, accurate cross-sectional images could not always be obtained using conventional two-dimensional images because airways run in various directions in the lung. Second, because investigators did not obtain longitudinal airway images, they could not recognize which generation of the bronchus they were actually measuring.

For this study, we developed new software for measuring airway dimensions using curved multiplanar reconstruction (MPR) by which we could obtain longitudinal images and accurately analyze short axis images of small airways with inner diameters as small as $2 \mathrm{~mm}$ located anywhere in the lung. Using the software, we analyzed the relationship between airflow limitation and airway dimensions up to the sixth generation of bronchi in the upper lobe and the lower lobe of patients with COPD. We found that airflow limitation in patients with COPD is more closely linked to the dimensions of distal airways than to those of proximal airways. Part of the preliminary results of the study has been previously reported in the form of an abstract (31).

\section{METHODS}

\section{CT Data Acquisition and Reconstruction}

CT scans were performed using a multidetector-row spiral CT scanner with four detector arrays (SOMATOME plus Volume Zoom; Siemens, Berlin, Germany). CT scans were acquired with the following parameters: $140 \mathrm{kVp}, 150 \mathrm{~mA}, 4$ detector $\times 1 \mathrm{~mm}$ collimation, and helical pitch 6 or 7. In this clinical study, the entire lung of each patient was scanned with patients in the supine position, holding their breaths at deep inspiration. All CT row data sets were reconstructed to isotropic voxel data using both soft-tissue and bone algorithms. The length of the 1-voxel side was $0.625 \mathrm{~mm}$. Reconstructed data were transferred to the workstation, and then reconstructed into three-dimensional chest images (AZE Ltd., Tokyo, Japan). First, a three-dimensional bronchial 
skeleton was automatically reconstructed using a certain threshold level in Hounsefield units (HU). The threshold level was determined on an individual basis ( -950 to $-980 \mathrm{HU})$ to obtain airway images as distal as possible. If some portions of lung parenchyma remained with the skeleton, they were manually removed to prevent an analysis error. Finally, we could obtain an accurate bronchial skeleton (Figure 1A) and could identify any bronchus in the source images of axial, sagittal, and coronal slices (Figure 1B). The selected bronchial pathway was automatically converted to a curved MPR image as shown in Figure 1C. The bronchial long-axis image appeared as a straight pathway. Of note, we could obtain short-axis images that were exactly perpendicular to the long axis at any site. In this study, a segmental bronchus was defined as the third generation of bronchus (Figure 1D). On the monitor of the workstation, image interpretation was done with a window width of 1,000 and a window level of -700 . From the centroid point of the lumen, rays fanning out over $360^{\circ}$ were examined to determine airway wall thickness along the rays using the full width at half-maximum principle $(16,32)$. After this process, if the outline of automatically obtained airway walls was obviously out of contour, it was then corrected. Based on manual plotting at several points, our software used cubic spline interpolation and built a new circle. Finally, we could get values for the airway luminal area (Ai) and the outer area of the bronchus (Ao). The wall area percent was defined as WA \% $=(\mathrm{Ao}-$ Ai) / Ao $\times 100$ (Figure 2A). As airway dimensions may be influenced by physical characteristics, we also assessed Ai after correcting for body surface area. Assuming that the airway lumen is true circle and airway wall thickness is constant throughout the wall, the inner diameter (Di), the total diameter (Do), and airway wall thickness (T) were calculated as $\mathrm{Di}=2 \sqrt{\mathrm{Ai}} / \pi, \mathrm{Do}=2 \mathrm{VAo} / \pi$ and $\mathrm{T}=(\mathrm{Do}-\mathrm{Di}) / 2$. All these analyses were done by one of the authors (M.H.) who was blinded to the subjects' background data.

\section{Phantom Study}

We did a validation study using three phantoms to test our newly developed software. The phantoms were made of acrylic resin, and their inner and outer diameters and wall thicknesses were optically accurate. Both phantom 1 and phantom 2 were cylindrical. Phantom 1 had an inner diameter of $2 \mathrm{~mm}$ and a wall thickness of $1 \mathrm{~mm}$ (Figure 2B). Phantom 2 had an inner diameter of $1.5 \mathrm{~mm}$ and a wall thickness of $1 \mathrm{~mm}$. Phantom $3 \mathrm{had}$ a sigmoid shape with an inner diameter of $3 \mathrm{~mm}$ and a wall thickness of $1 \mathrm{~mm}$ (Figure 2C). Phantom 3 was used to prove the accuracy of the algorithm, which should allow the short axis images to be obtained exactly perpendicular to the long axis at any site. When doing the CT scans, the phantoms were placed into polystyrene foam blocks, representing the lung parenchyma. CT scans were performed under the same conditions as those used in the clinical study.

\section{Subjects}

The subjects in this study had been recruited from 2003 through 2005 as part of the Hokkaido COPD cohort study, the results of which will be the subject of a separate paper. A diagnosis of COPD was made based upon the GOLD guideline (1). Subjects who had an allergic diathesis, an episodic wheeze, or a history of bronchial asthma were excluded from this study. A total of 52 COPD patients in various clinical stages according to the GOLD criteria (stage I, $\mathrm{n}=14$; stage II, $\mathrm{n}=$ 22 ; stage III, $\mathrm{n}=14$; stage IV, $\mathrm{n}=2$ ) were enrolled. There were only two subjects with stage IV disease because we excluded patients on long-term oxygen therapy from our cohort study. All subjects gave their written informed consent. The subjects' characteristics are shown in Table 1 . This study was approved by the Health Authority Research Ethics Committee of Hokkaido University.

\section{Pulmonary Function Tests}

Most pulmonary function tests were obtained on the same day as the $\mathrm{CT}$, but some were done within a week before or after the CT. We used the rolling seal type of spirometers CHESTAC-33 (CHEST M.I., Inc., Tokyo, Japan). The results of pulmonary function tests met the requirements of the Japanese Respiratory Society guideline (33), which are similar to those of the ATS. In brief, three acceptable and two reproducible maneuvers were required from up to eight forced expirations. Inhalation of short-acting bronchodilators in the previous $12 \mathrm{~h}$ was prohibited; treatment with long-acting $\beta_{2}$-agonists or sustainedrelease theophyllines in the previous $24 \mathrm{~h}$ was also prohibited. A longacting anticholinergic inhaler was not available in Japan at the time of this study. Acceptable maneuvers were defined as those with peak

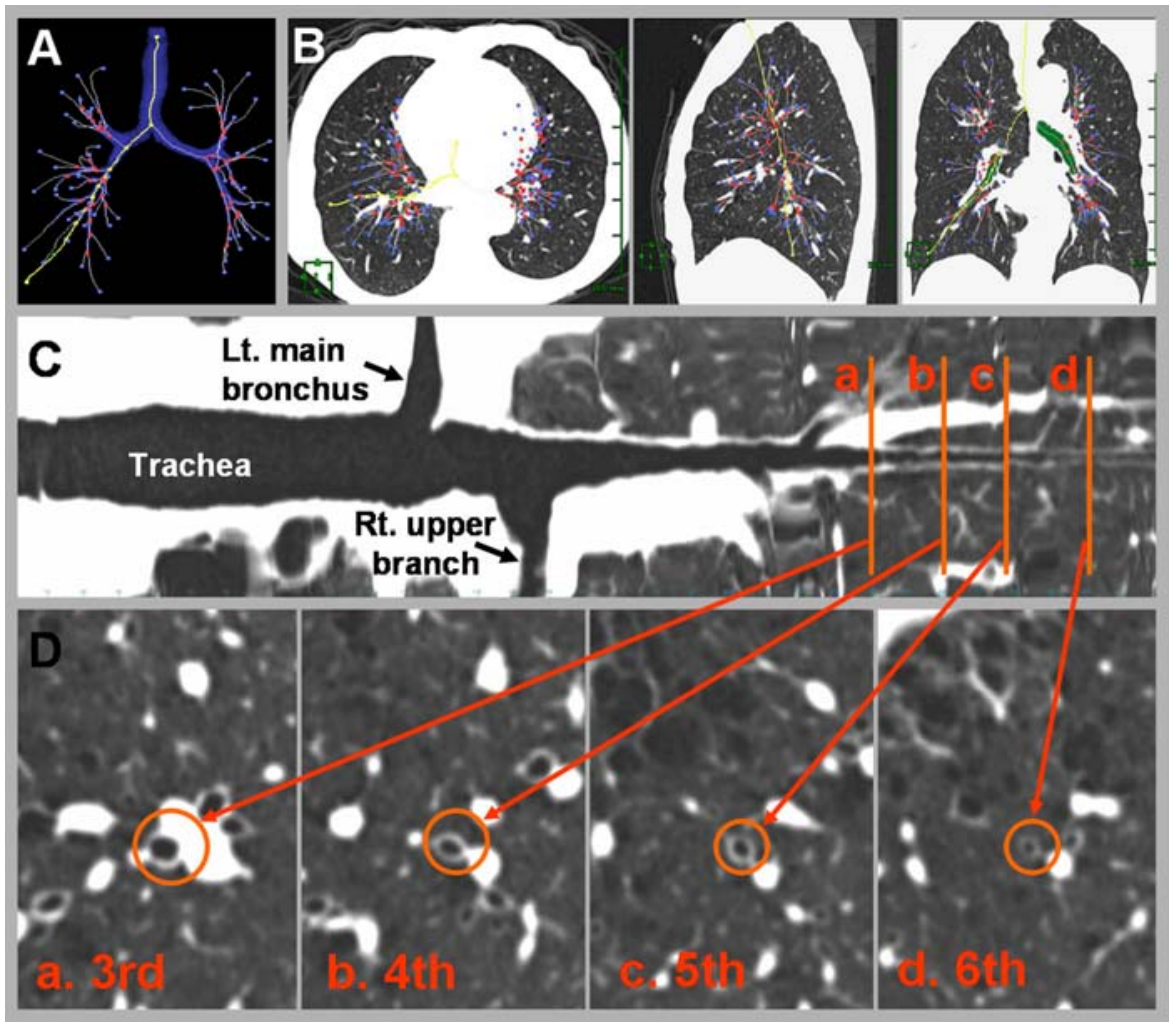

Figure 1. (A) Accurate bronchial skeleton. (B) Source images of axial, sagittal, and coronal slices. Yellow lines indicate the same series of airway in both $A$ and $B$. (C) A curved MPR image of the selected airway (B8) from the right lower lobe. $(D)$ Short-axis images obtained from the curved MPR image are precisely perpendicular to the long axis of the airway. The numbers of the bronchial generation are shown (see text for details). 

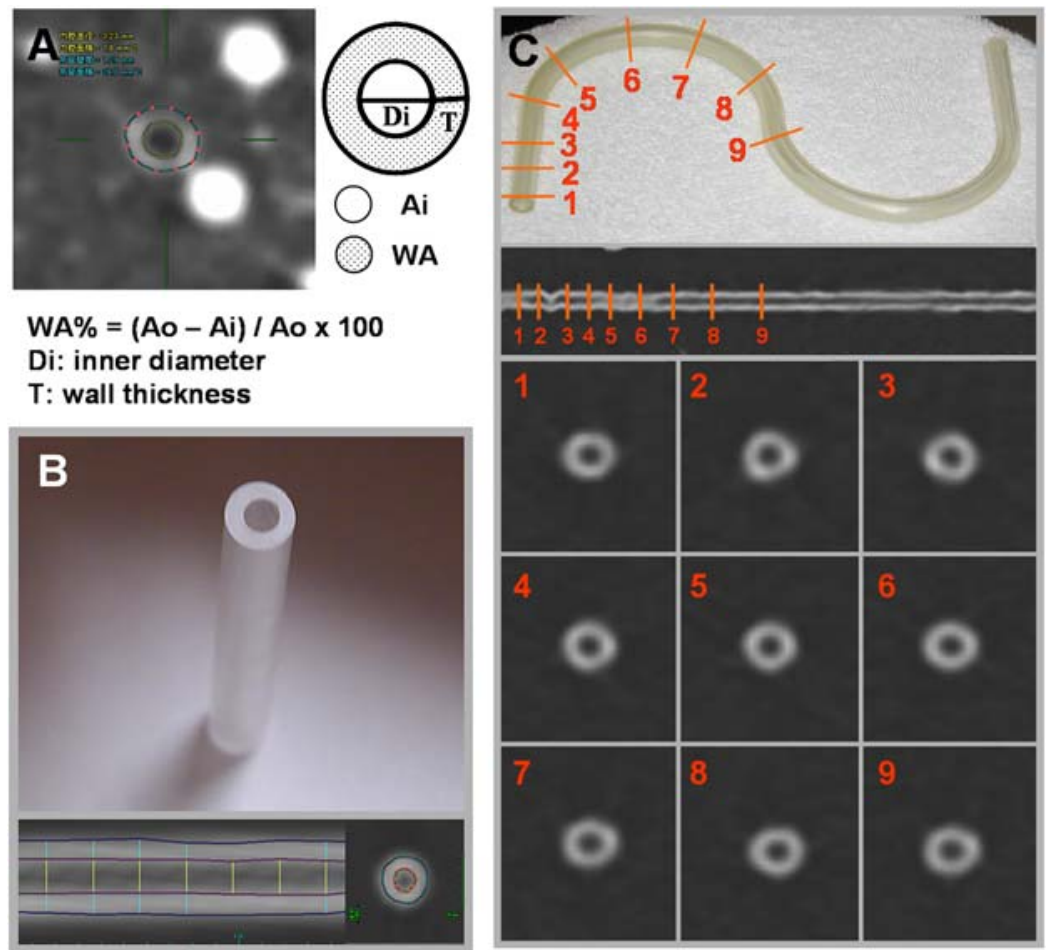

Figure 2. (A) A representative case shows the measurement of airway dimensions on the short-axis image. Airway wall thickness was determined using the full width at halfmaximum principle; we could obtain the outline of airway walls automatically (see text for details). The schema of the short-axis image shows the airway luminal area (Ai) and the airway wall area (WA). The ratio of wall area was calculated as WA / the outer area of the bronchus $(\mathrm{Ao}) \times 100$. (B) A photograph of a column-shaped phantom with a 2-mm inner diameter and a 1-mm wall thickness (upper). A curved MPR image of the phantom and a short-axis image (lower). (C) A photograph of the sigmoid-shaped phantom with a 3-mm inner diameter (upper). A curved MPR image obtained from original CT data (middle). Nine short-axis images at various sites (lower). expiratory flow within $10 \%$ of the maximum observed, a rapid start, absence of major flow fluctuations, and adequate expiration time. Reproducible maneuvers agreed within $200 \mathrm{ml}$ of the larger $\mathrm{FEV}_{1}$. The $\mathrm{FEV}_{1}$ and forced vital capacity (FVC) values taken to characterize each participant were the maximum results obtained from acceptable maneuvers. $\mathrm{FEV}_{1}$ and $\mathrm{FVC}$ were expressed as percentage of predicted values according to the prediction equations of the Japanese Respiratory Society (33). The diffusing capacity of the lung for carbon monoxide $\left(\mathrm{DL}_{\mathrm{CO}}\right)$ based on the single-breath method was also measured in all subjects according to the pulmonary function test guideline of the Japanese Respiratory Society (33). $\mathrm{DL}_{\mathrm{CO}}$ divided by alveolar volume was expressed as percentage of predicted values according to the prediction equations of Burrows (34). Lung volumes-total lung capacity (TLC), functional residual capacity (FRC), and residual volume (RV)-were measured by the helium-closed-circuit method. Lung volumes were expressed as percentage of predicted values according to the prediction equations of Nishida (35)

\section{TABLE 1. CHARACTERISTICS OF THE SUBJECTS}

\begin{tabular}{|c|c|c|c|c|}
\hline Sex* & & Median (Mean) & Range & SD \\
\hline Age & $\mathrm{yr}$ & $72(70)$ & $41-84$ & $y$ \\
\hline Height & $\mathrm{cm}$ & $164(164)$ & $139-177$ & 7 \\
\hline Weight & $\mathrm{kg}$ & $61(61)$ & $31-77$ & 9 \\
\hline Smoking & pack-years & $57(63)$ & $21-174$ & 29 \\
\hline FVC & $\%$ predicted & $94(90)$ & $59-158$ & 21 \\
\hline $\mathrm{FEV}_{1} / \mathrm{FVC}$ & $\%$ & $47(50)$ & $26-69$ & 13 \\
\hline $\mathrm{FEV}_{1}$ & $\%$ predicted & $55(64)$ & $23-120$ & 25 \\
\hline TLC & $\%$ predicted & $113(113)$ & $84-160$ & 17 \\
\hline FRC & $\%$ predicted & 119 (125) & $85-180$ & 24 \\
\hline RV & $\%$ predicted & $137(141)$ & $67-250$ & 39 \\
\hline $\mathrm{RV} / \mathrm{TLC}$ & $\%$ & $46(46)$ & $25-65$ & 10 \\
\hline$D \mathrm{~L}_{\mathrm{CO}} / \mathrm{VA}$ & $\%$ predicted & 72 (70) & $27-109$ & 22 \\
\hline
\end{tabular}

* The subjects were 50 males and 2 females.

Definition of abbreviations: $\mathrm{DL}_{\mathrm{CO}}=$ carbon monoxide diffusing capacity; $\mathrm{FEV}_{1}=$ forced expiratory volume in $1 \mathrm{~s} ; \mathrm{FRC}=$ functional residual capacity; $F V C=$ forced vital capacity; RV = residual volume; TLC = total lung capacity; $\mathrm{VA}=$ alveolar volume.

\section{Statistical Analysis}

All statistical analyses were done using Pearson correlation coefficients. Results are expressed as mean $\pm \mathrm{SD}$. Linear regression analysis was used to evaluate the relationship between the airway parameters and $\mathrm{FEV}_{1}$ (\% predicted). A value of $\mathrm{p}$ less than 0.05 was considered to be significant.

\section{RESULTS}

\section{Validation Study of the Software Using Phantoms}

For phantom 1, Ai was $2.8 \pm 0.1 \mathrm{~mm}^{2}$ and WA was $9.8 \pm 0.2 \mathrm{~mm}^{2}$, both of which were close to the actual values $\left(3.1 \mathrm{~mm}^{2}\right.$ and $9.4 \mathrm{~mm}^{2}$, respectively) (Table 2). The coefficients of variation for Ai and WA were $2.8 \%$ and $2.2 \%$, respectively; both were well within acceptable limits. On the other hand, for phantom 2, whose inner diameter was $1.5 \mathrm{~mm}$, the coefficient of variation was $14.9 \%$ for $\mathrm{Ai}$ and $3.5 \%$ for WA; the coefficient of variation for Ai was not as good as that obtained with phantom 1 , whose inner diameter was 2 $\mathrm{mm}$. These data indicate that the measurement of airway dimensions by our new software is very accurate and reproducible for airways with an inner diameter $\geqslant 2 \mathrm{~mm}$. To confirm how

TABLE 2. VARIABILITY OF THE DATA IN THE MEASUREMENTS OF THE PHANTOMS

\begin{tabular}{lllrr}
\hline & & & Values Measured \\
& & $n$ & $2.8 \pm 0.1$ & $C V$ \\
\hline Phantom 1 & $\mathrm{Ai}$ & 10 & $9.8 \pm 0.2$ & $2.8 \%$ \\
& $\mathrm{WA}$ & 10 & $1.7 \pm 0.2$ & $2.2 \%$ \\
Phantom 2 & $\mathrm{Ai}$ & 10 & $8.4 \pm 0.3$ & $14.9 \%$ \\
& $\mathrm{WA}$ & 10 & $6.8 \pm 0.8$ & $3.5 \%$ \\
Phantom 3 & $\mathrm{Ai}$ & 40 & $13.2 \pm 0.2$ & $3.3 \%$ \\
& WA & 40 & & $2.5 \%$ \\
\hline
\end{tabular}

Definition of abbreviations: $\mathrm{A}$ = airway luminal area; $\mathrm{CV}=$ coefficient of variation; $\mathrm{WA}=$ wall area 
accurately we could get precise short-axis images of bronchi that run in various directions in the lung, we obtained images of the sigmoid-shaped phantom (phantom 3). Axial images of phantom 3 obtained at any point were perfect, round shapes (Figure 2C), confirming that the software can be used for any bronchi. Data was obtained from 40 points of the sigmoid-shaped phantom, which had an Ai of $7.1 \mathrm{~mm}^{2}$ and a WA of $12.6 \mathrm{~mm}^{2}$; the measured Ai was $6.8 \pm 0.8 \mathrm{~mm}^{2}$, and the WA was $13.2 \pm 0.2 \mathrm{~mm}^{2}$. The coefficients of variation for $\mathrm{Ai}$ and WA were $3.3 \%$ and $2.5 \%$, respectively; both of these values were considered acceptable for human studies.

\section{Studies on Airway Measurements in Patients with COPD}

To measure airway dimensions in patients with COPD, we selected two bronchi, the apical bronchus (B1) of the right upper lobe and the anterior basal bronchus (B8) of the right lower lobe. The mean inner diameter of the sixth generation in both B1 and B8 was calculated to be approximately $2.3 \mathrm{~mm}$. Because the phantom studies demonstrated that the airways with an inner diameter as small as $2.0 \mathrm{~mm}$ could be accurately measured, we decided to sample airways from the third to the sixth generations. For B1, Ai of the third to the sixth generation ranged from $19.5 \pm$ $12.1 \mathrm{~mm}^{2}$ to $4.3 \pm 2.5 \mathrm{~mm}^{2}$ (mean $\pm \mathrm{SD}$ ); for $\mathrm{B} 8$, Ai ranged from $16.3 \pm 7.4 \mathrm{~mm}^{2}$ to $4.3 \pm 2.4 \mathrm{~mm}^{2}$ (Table 3 ). The measured value of WA and the calculated values of Di and T are also listed in Table 3. The Ai of all generations except for the third generation of B1 had a significant positive correlation with $\mathrm{FEV}_{1}$ (\% predicted). The WA \% of all generations except the third and fourth generations of $\mathrm{B} 1$ had a significant negative correlation with $\mathrm{FEV}_{1}$ (\% predicted). For both $\mathrm{Ai}$ and $\mathrm{WA} \%$, the correlation coefficients improved as the airways became smaller. Furthermore, in comparisons of the $\mathrm{Ai}$ and $\mathrm{WA} \%$ of $\mathrm{B} 1$ with those of $\mathrm{B} 8$, the $\mathrm{B} 8$ indices generally had better correlations with $\mathrm{FEV}_{1}$ (\% predicted) than the $\mathrm{B} 1$ indices (Table 3 ). Correcting the $\mathrm{Ai}$ by body surface area made little difference in terms of $r$ values, although the corrected $r$ values were slightly lower in comparison with the values before correction. Representative data illustrate the characteristic differences between the third and sixth generations in Figure 3. For correlations of the other parameters of lung function with the airway dimensions see Tables E1 and E2 in the online supplement. FVC (\% predicted), $\mathrm{FEV}_{1} / \mathrm{FVC}, \mathrm{RV}$ (\% predicted), and RV/TLC, which are the parameters for airflow limitation, showed similar tendency with $\mathrm{Ai}$ or WA $\%$ for $\mathrm{FEV}_{1}(\%$ predicted) in both B1 and B8. However, FEV $(\%$ predicted) showed generally better correlations with airway di- mensions than any other pulmonary function parameter. On the other hand, none of the airway dimension parameters showed a statistically significant correlation with $\mathrm{DL}_{\mathrm{CO}}$ /alveolar volume, TLC ( $\%$ predicted), or FRC (\% predicted).

\section{Variance of Airway Measurement}

Even in the same bronchial skeleton, at each bifurcation we had to select one branch among the two or three branches of the same generation and then decide on locating a short-axis image around the center between two successive bifurcations. This process allows one to obtain slightly different axial images, potentially causing unwanted bias. Thus, to assess the variance of the measurements for the same generation of bronchi in the same subjects, we performed the following study. We selected eight subjects with various COPD stages and measured $\mathrm{Ai}$ and WA \% six times in each selected bronchus (Figure 4). The coefficients of variation for the measurements of $\mathrm{Ai}$ from the third to the sixth generation were $9.0 \pm 4.3 \%, 10.5 \pm 5.3 \%, 10.4 \pm$ $5.0 \%$, and $14.9 \pm 9.1 \%$ in $\mathrm{B} 1$, and $6.5 \pm 3.0 \%, 11.2 \pm 5.4 \%$, $11.5 \pm 7.2 \%$, and $13.0 \pm 4.4 \%$ in $\mathrm{B} 8$. The coefficients of variation of WA $\%$ from the third to the sixth generation were $6.1 \pm 3.2 \%$, $6.5 \pm 3.0 \%, 6.3 \pm 3.0 \%$, and $5.5 \pm 4.1 \%$ in B1, and $6.2 \pm 2.7 \%$, $6.9 \pm 4.2 \%, 7.2 \pm 3.4 \%$, and $5.8 \pm 1.8 \%$ in B8. As with the results obtained from all 52 subjects, we found statistically significant correlations of $\mathrm{FEV}_{1}$ (\% predicted) and the two parameters of the sixth generation of B1 and B8. Additionally, both Ai and WA $\%$ in the third generation of the bronchi showed statistically significant correlations with $\mathrm{FEV}_{1}$ (\% predicted) in $\mathrm{B} 8$ but not in B1, which was again consistent with the data obtained from all the subjects. These results suggest that one-site measurement around the center of one targeted branch reasonably reflects the dimensions of each branch with negligible bias.

\section{DISCUSSION}

In this study, we developed new software using curved MPR for depicting a three-dimensional airway skeleton and measuring luminal areas of airways and wall areas very precisely at any site in the lungs. Using phantoms, we demonstrated that we could obtain accurate short images with an inner diameter as small as $2 \mathrm{~mm}$ and a wall thickness of $1 \mathrm{~mm}$, and that the shortaxis images obtained were precisely perpendicular to the long axis even with a sigmoid-shaped phantom. We thus did not need to consider the obliquity of targeted airways. We then measured airway dimensions in patients with COPD of various clinical

TABLE 3. AIRWAY DIMENSIONS AND THEIR RELATIONSHIP WITH FEV 1 (\% PREDICTED)

\begin{tabular}{|c|c|c|c|c|c|c|c|}
\hline & \multicolumn{2}{|c|}{ Measurements } & \multicolumn{2}{|c|}{ Calculated values } & \multicolumn{3}{|c|}{$\begin{array}{l}\text { Correlation coefficients }(r) \text { with } \\
\qquad \text { FEV }_{1} \text { (\% predicted) }\end{array}$} \\
\hline & $\mathrm{Ai}\left(m m^{2}\right)$ & WA $\left(m m^{2}\right)$ & $\mathrm{Di}(\mathrm{mm})$ & $\mathrm{T}(m m)$ & $\mathrm{Ai}$ & Ai/BSA & WA (\%) \\
\hline \multicolumn{8}{|c|}{ Upper (B1) } \\
\hline $3 r d$ & $19.5 \pm 12.1$ & $26.3 \pm 9.3$ & $4.8 \pm 1.2$ & $1.3 \pm 0.3$ & 0.258 & 0.178 & -0.224 \\
\hline 4 th & $10.2 \pm 4.7$ & $17.4 \pm 5.9$ & $3.5 \pm 0.8$ & $1.2 \pm 0.2$ & $0.371^{*}$ & 0.247 & -0.260 \\
\hline 5 th & $6.4 \pm 2.8$ & $12.7 \pm 3.8$ & $2.8 \pm 0.6$ & $1.1 \pm 0.2$ & $0.577^{\dagger}$ & $0.471^{\dagger}$ & $-0.477^{\dagger}$ \\
\hline 6th & $4.3 \pm 2.4$ & $9.5 \pm 3.0$ & $2.3 \pm 0.6$ & $0.9 \pm 0.2$ & $0.637^{\dagger}$ & $0.554^{\dagger}$ & $-0.552^{\dagger}$ \\
\hline \multicolumn{8}{|c|}{ Lower (B8) } \\
\hline $3 r d$ & $16.3 \pm 7.4$ & $22.9 \pm 8.9$ & $4.4 \pm 1.0$ & $1.3 \pm 0.3$ & $0.596^{\dagger}$ & $0.495^{\dagger}$ & $-0.429^{*}$ \\
\hline 4 th & $9.2 \pm 4.4$ & $15.7 \pm 5.4$ & $3.3 \pm 0.8$ & $1.1 \pm 0.2$ & $0.651^{\dagger}$ & $0.584^{\dagger}$ & $-0.485^{\dagger}$ \\
\hline 5 th & $5.9 \pm 3.0$ & $11.4 \pm 3.6$ & $2.7 \pm 0.6$ & $1.0 \pm 0.2$ & $0.627^{\dagger}$ & $0.590^{\dagger}$ & $-0.488^{\dagger}$ \\
\hline 6th & $4.3 \pm 2.5$ & $9.1 \pm 3.9$ & $2.3 \pm 0.6$ & $0.9 \pm 0.2$ & $0.731^{\dagger}$ & $0.703^{\dagger}$ & $-0.547^{\dagger}$ \\
\hline
\end{tabular}

Values are mean \pm SD.

Correlation coefficients are shown $\left({ }^{*} p<0.01 ;{ }^{\dagger} p<0.001\right)$.

Definition of abbreviations: $\mathrm{Ai}=$ airway luminal area; $\mathrm{B} 1=$ apical bronchus; $\mathrm{B} 8=$ anterior basal bronchus; $\mathrm{BSA}=$ body surface area; $\mathrm{Di}=$ inner diameter; $\mathrm{T}=$ airway wall thickness; $\mathrm{WA}=$ airway wall area 

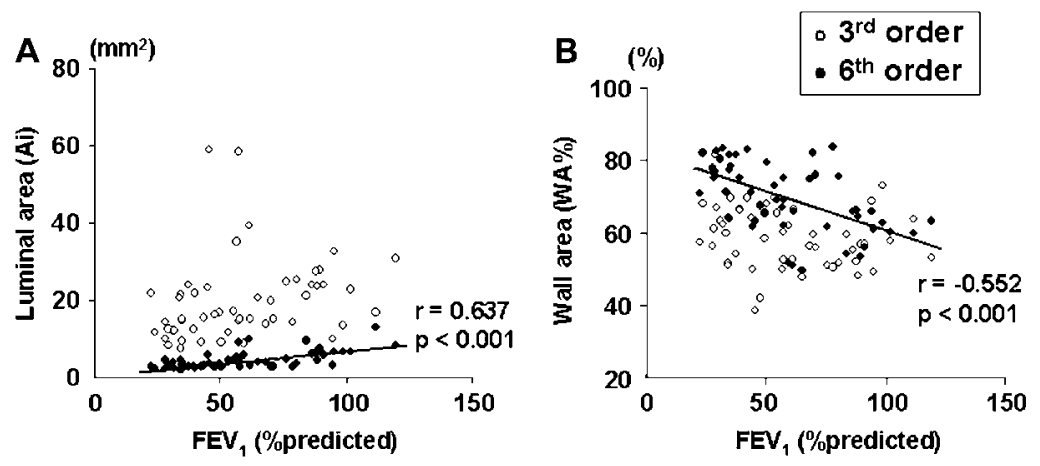

Figure 3. Representative data illustrate the characteristic difference between the third and sixth generations. Relationship of $\mathrm{FEV}_{1}(\%$ predicted), airway luminal area (Ai), and wall area percent (WA \%) in 52 patients with COPD. $(A, B)$ Apical bronchus (B1) of the right upper lobe. $(C, D)$ Anterior basal bronchus (B8) of the right lower lobe. Open
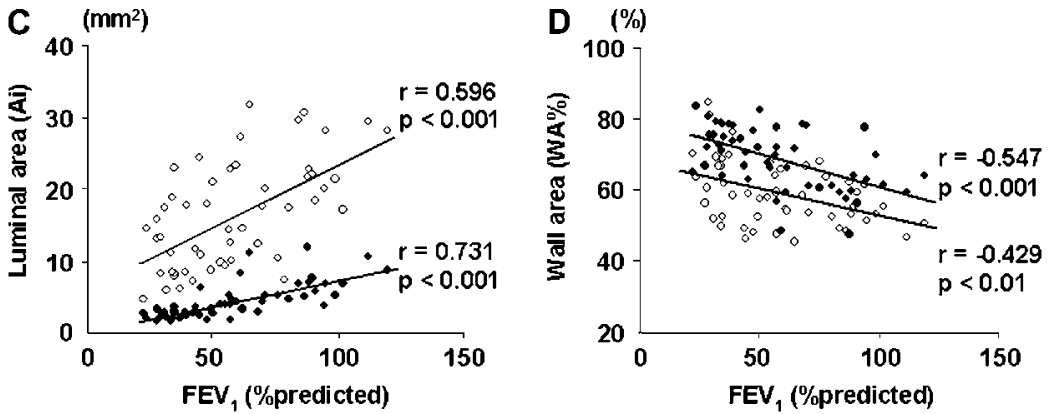
circles, third generation; filled circles, sixth generation. The correlation coefficients between airflow limitation and airway dimensions are better in the sixth generation than in the third generation of both $\mathrm{B} 1$ and $\mathrm{B} 8$.

stages. Although in this study we examined only two bronchi, one from B1 of the right upper lobe and the other from B8 of the right lower lobe, we demonstrated that the values of $\mathrm{Ai}$ and WA \% correlated well with $\mathrm{FEV}_{1}$ (\% predicted). More importantly, the correlation coefficients between both airway parameters and $\mathrm{FEV}_{1}$ (\% predicted) improved as the airway size decreased from the third to the sixth generation both in B1 and B8. These results clearly support the concept that distal (small) airways rather than proximal (large) airways are the more important determinant of airflow limitation in COPD, as has been previously suggested by a number of pathology-function correlation studies in the past (11-14).

To the best of our knowledge, this is the first three-dimensional CT study to demonstrate the relationship between the airflow limitation index and the dimensions of various-sized airways in patients with COPD. It was the software using curved MPR that allowed us to do so. Although the idea of threedimensional analysis is not entirely new $(22,36-38)$, it has not been applied to measuring airway dimensions in patients with COPD. In COPD, the quantitative evaluation of the airways
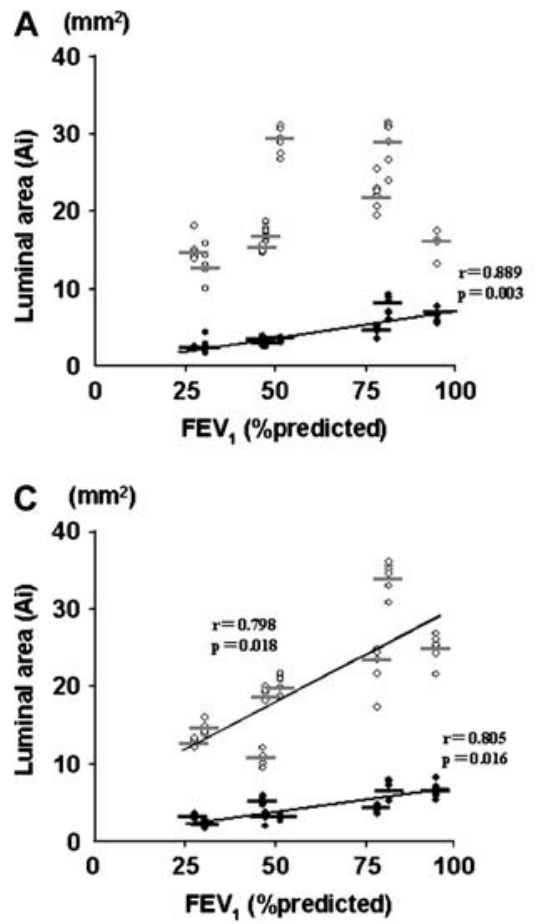

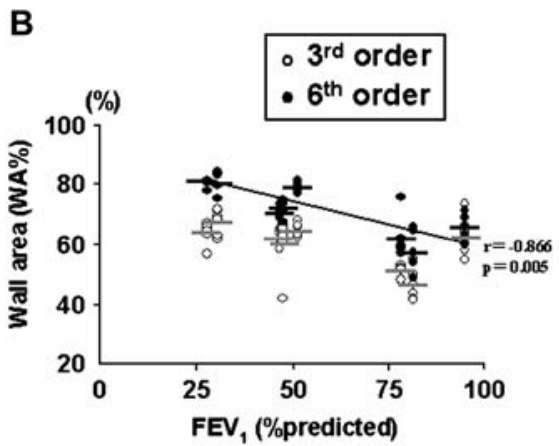

D

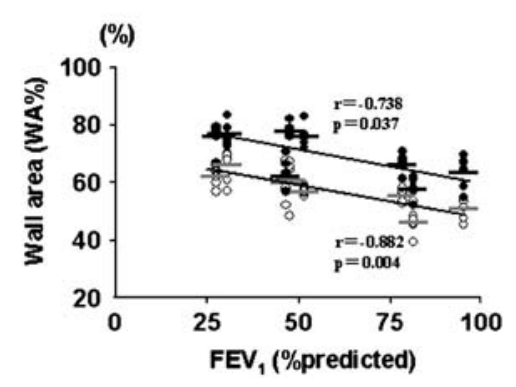

Figure 4. The same generation of bronchi was measured six times in eight patients with COPD. Bars indicate the averages of the individual data. $(A, B)$ Apical bronchus (B1) of the right upper lobe. $(C, D)$ Anterior basal bronchus (B8) of right lower lobe. Open circles, third generation; filled circles, sixth generation; $\mathrm{Ai}$, airway luminal area; WA\%, wall area percent. 
using CT has received less attention than the analysis of emphysema. In fact, there have been only a few such studies (27-30). Nakano and colleagues were the first to report that wall thickening at $\mathrm{B} 1$ in the right upper lobe had a significant correlation with $\mathrm{FEV}_{1}$ (\% predicted) (27), and they subsequently demonstrated that measuring airway dimensions in large airways could roughly estimate small airway dimensions by comparing the CT findings of large airways with the histologic measurement of small airways in lungs excised from the same subjects (28). The important role of small airway lesions in COPD airflow limitation has been long recognized (11-14). In an earlier study, Hogg and colleagues used a retrograde catheter technique and were the first to report that the resistance in small airways of excised lungs from patients with COPD was greatly increased compared with normal lungs, in which $25 \%$ of the total airway resistance is accounted for by the small airways (11). They further demonstrated that the resistance correlated with the histologic findings of narrowing and obliteration of small airways along with mucous plugging. Very recently, Hogg and colleagues again demonstrated that, in surgically excised lungs, the severity of small airway disease paralleled the COPD clinical stage as defined by airflow limitation (14). The obstruction of the small airways consists of airway-wall thickening that occurs through a remodeling process and airway narrowing due to the accumulation of inflammatory cells and exudates in the lumen. The current study confirms that the inner area and, to a lesser extent, the wall area in distal (small) airways, rather than proximal (large) airways, are closely related to the severity of airflow limitation in vivo in patients with COPD. In contrast to Nakano and colleagues (27), we did not find a statistically significant correlation between $\mathrm{FEV}_{1}$ (\% predicted) and $\mathrm{WA} \%$ in the third generation of $\mathrm{B} 1$, though a similar trend was observed in our study. However, the correlation coefficients that we obtained for the fifth and sixth generations were as high as 0.6 to 0.7 , which are much better than the correlation coefficient (0.338) that they obtained in the third generation of B1 in their study.

Of note, the airway luminal area, Ai, is not a pure index of airway disease itself, particularly when measured in vivo. Rather, it is influenced by several direct or indirect factors. Certainly, airway-wall thickening contributes to airway narrowing $(39,40)$. Secretions or exudates within the airway luminal area may further contribute to airway narrowing. In addition, airway caliber is influenced by the pressure balance between the inside and the outside of the airway walls $(1,41)$. This would particularly hold true for small airways, which lack cartilage in their walls. In our study, we measured airway dimensions while subjects were holding their breath at deep inspiration. Therefore, the elastic recoil pressure of the surrounding tissue may also have influenced airway caliber. For instance, if the airway being measured was surrounded by lung destruction (emphysema), this would contribute to further airway narrowing as a consequence of lowered elastic recoil pressure in addition to the presence of airway disease. This factor may account for the relatively higher correlation coefficients of $\mathrm{Ai}$ and $\mathrm{FEV}_{1}$ (\% predicted) than of $\mathrm{WA} \%$ and $\mathrm{FEV}_{1}$ (\% predicted) in our study. Unfortunately, our current software does not permit us to measure the dynamic change in airway caliber in association with respiration.

It should also be noted that the correlations of airflow limitation were generally better with the airway dimensions of B8 than with those of B1. This may be due to the fact that the volume of the lower lobe associated with B8 is larger than that of the upper lobe associated with B1. Consistent with this finding, it has been reported that the volume of the lower lobes contributes more to general pulmonary function than the volume of the upper lobes in patients with COPD (42).
Finally, we should mention some limitations of this study. First, we assessed only two bronchi, B1 and B8. Variation in airway dimensions may exist even in the lungs of normal subjects (43). On the other hand, King and colleagues recently reported that airway narrowing after a methacholine challenge varied in the large airways of asthmatics and normal subjects but not in the small airways (44), and Kim and colleagues reported that no statistically significant differences were found in the inner diameter of the bronchus divided by its outer diameter among segments, lobes, and lungs in normal subjects (45). Nevertheless, further extensive studies are definitely required to examine possible variations in airway dimensions in COPD. Second, we did not perform another validation study of the new software, which would have ideally compared the airway dimensions obtained by CT measurements with those of excised lung specimens. However, because the data we obtained using the phantoms was so encouraging, we proceeded to the human study. We are currently improving the power of the software so that it can be used with the more advanced multidetector CT scanners.

In conclusion, we developed new software using curved MPR to analyze airway dimensions exactly perpendicular to the long axis of airways at any site in the lungs. Using this software, we have for the first time demonstrated in vivo in patients with COPD that $\mathrm{FEV}_{1}$ (\% predicted) was highly correlated with airway luminal area and, to a lesser extent, with wall thickening from the third to the sixth generation of both $\mathrm{B} 1$ and $\mathrm{B} 8$, and that the correlation coefficients improved as airway size decreased. In the near future, with further advances in CT technology and in software, this type of approach will become even more attractive. Using this readily accessible and relatively noninvasive technique, we plan to conduct a longitudinal study of the subjects recruited for the Hokkaido COPD cohort study.

Conflict of Interest Statement: None of the authors has a financial relationship with a commercial entity that has an interest in the subject of this manuscript.

Acknowledgment: The authors thank the staffs of the central office of the Hokkaido COPD Cohort Study and of the Division of Pulmonary Function, the Department of Laboratory Medicine, Hokkaido University Hospital.

\section{References}

1. Global Initiative for Chronic Obstructive Lung Disease (GOLD). Global strategy for the diagnosis, management, and prevention of chronic obstructive pulmonary disease, updated 2003. Bethesda, MD: National Heart, Lung and Blood Institute, World Health Organization; 2003.

2. Yoshioka A, Betsuyaku T, Nishimura M, Miyamoto K, Kondo T, Kawakami Y. Excessive neutrophil elastase in bronchoalveolar lavage fluid in subclinical emphysema. Am J Respir Crit Care Med 1995;152: 2127-2132.

3. Betsuyaku T, Nishimura M, Takeyabu K, Tanino M, Venge P, Xu S, Kawakami Y. Neutrophil granule proteins in bronchoalveolar lavage fluid from subjects with subclinical emphysema. Am J Respir Crit Care Med 1999;159:1985-1991.

4. Bergin C, Müller N, Nichols DM, Lillington G, Hogg JC, Mullen B, Grymaloski MR, Osborne S, Paré PD. The diagnosis of emphysema: a computed tomographic-pathologic correlation. Am Rev Respir Dis 1986;133:541-546.

5. Müller NL, Staples CA, Miller RR, Abboud RT. "Density mask": an objective method to quantitate emphysema using computed tomography. Chest 1988;94:782-787.

6. Kuwano K, Matsuba K, Ikeda T, Murakami J, Araki A, Nishitani H, Ishida T, Yasumoto K, Shigematsu N. The diagnosis of mild emphysema: correlation of computed tomography and pathology scores. Am Rev Respir Dis 1990;141:169-178.

7. Gevenois PA, de Maertelaer V, De Vuyst P, Zanen J, Yernault JC. Comparison of computed density and macroscopic morphometry in pulmonary emphysema. Am J Respir Crit Care Med 1995;152:653-657.

8. Gevenois PA, De Vuyst P, Sy M, Scillia P, Chaminade L, de Maertelaer V, Zanen J, Yernault JC. Pulmonary emphysema: quantitative CT during expiration. Radiology 1996;199:825-829. 
9. Coxson HO, Rogers RM, Whittall KP, D’Yachkova Y, Paré PD, Sciurba FC, Hogg JC. A quantification of the lung surface area in emphysema using computed tomography. Am J Respir Crit Care Med 1999;159: 851-856.

10. Baldi S, Miniati M, Bellina CR, Battolla L, Catapano G, Begliomini E, Giustini D, Giuntini C. Relationship between extent of pulmonary emphysema by high-resolution computed tomography and lung elastic recoil in patients with chronic obstructive pulmonary disease. Am J Respir Crit Care Med 2001;164:585-589.

11. Hogg JC, Macklem PT, Thurlbeck WM. Site and nature of airway obstruction in chronic obstructive lung disease. N Engl J Med 1968;278:13551360.

12. Van Brabandt H, Cauberghs M, Verbeken E, Moerman P, Lauweryns JM, Van de Woestijne KP. Partitioning of pulmonary impedance in excised human and canine lungs. J Appl Physiol 1983;55:1733-1742.

13. Yanai M, Sekizawa K, Ohrui T, Sasaki H, Takishima T. Site of airway obstruction in pulmonary disease: direct measurement of intrabronchial pressure. J Appl Physiol 1992;72:1016-1023.

14. Hogg JC, Chu F, Utokaparch S, Woods R, Elliott WM, Buzatu L, Cherniack RM, Rogers RM, Sciurba FC, Coxson HO, et al. The nature of small-airway obstruction in chronic obstructive pulmonary disease. $N$ Engl J Med 2004;350:2645-2653.

15. Grenier PA, Beigelman-Aubry C, Fetita C, Preteux F, Brauner MW, Lenoir S. New frontiers in CT imaging of airway disease. Eur Radiol 2002;12:1022-1044.

16. de Jong PA, Muller NL, Parè PD, Coxson HO. Computed tomographic imaging of the airways: relationship to structure and function. Eur Respir J 2005;26:140-152.

17. Coxson HO, Rogers RM. New concepts in the radiological assessment of COPD. Semin Respir Crit Care Med 2005;26:211-220.

18. Onodera Y, Omatsu T, Takeuchi S, Shinagawa N, Yamazaki K, Nishioka T, Miyasaka K. Enhanced virtual bronchoscopy using the pulmonary artery: improvement in route mapping for ultraselective transbronchial lung biopsy. AJR Am J Roentgenol 2004;183:1103-1110.

19. Shinagawa N, Yamazaki K, Onodera Y, Miyasaka K, Kikuchi E, DosakaAkita H, Nishimura M. CT-guided transbronchial biopsy using an ultrathin bronchoscope with virtual bronchoscopic navigation. Chest 2004;125:1138-1143.

20. Asahina H, Yamazaki K, Onodera Y, Kikuchi E, Shinagawa N, Asano F, Nishimura M. Transbronchial biopsy using endobronchial ultrasonography with a guide sheath and virtual bronchoscopic navigation. Chest 2005;128:1761-1765.

21. Niimi A, Matsumoto H, Amitani R, Nakano Y, Mishima M, Minakuchi M, Nishimura K, Itoh H, Izumu T. Airway wall thickness in asthma assessed by computed tomography: relation to clinical indices. Am J Respir Crit Care Med 2000;162:1518-1523.

22. Hoffman EA, Reinhardt JM, Sonka M, Simon BA, Guo J, Saba O, Chon D, Samrah S, Shikata H, Tschirren J, et al. Characterization of the interstitial lung diseases via density-based and texture-based analysis of computed tomography images of lung structure and function. Acad Radiol 2003;10:1104-1118.

23. Ernst A, Feller-Kopman D, Becker HD, Mehta AC. Central airway obstruction. Am J Respir Crit Care Med 2004;169:1278-1297.

24. Martinez TM, Llapur CJ, Williams TH, Coates C, Gunderman R, Cohen MD, Howenstine MS, Saba O, Coxson HO, Tepper RS. High-resolution computed tomography imaging of airway disease in infants with cystic fibrosis. Am J Respir Crit Care Med 2005;172:1133-1138.

25. de Jong PA, Nakano Y, Hop WC, Long FR, Coxson HO, Paré PD, Tiddens HA. Changes in airway dimensions on computed tomography scans of children with cystic fibrosis. Am J Respir Crit Care Med 2005; 172:218-224.

26. Brody AS, Tiddens HA, Castile RG, Coxson HO, de Jong PA, Goldin J, Huda W, Long FR, McNitt-Gray M, Rock M, et al. Computed tomography in the evaluation of cystic fibrosis lung disease. Am J Respir Crit Care Med 2005;172:1246-1252.

27. Nakano Y, Muro S, Sakai H, Hirai T, Chin K, Tsukino M, Nishimura K, Ito H, Pare PD, Hogg JC, Mishima M. Computed tomographic measurements of airway dimensions and emphysema in smokers: correlation with lung function. Am J Respir Crit Care Med 2000;162:11021108.

28. Nakano Y, Wong JC, de Jong PA, Buzatu L, Nagao T, Coxson HO, Elliott WM, Hogg JC, Pare PD. The prediction of small airway dimensions using computed tomography. Am J Respir Crit Care Med 2005; 171:142-146.

29. Orlandi I, Moroni C, Camiciottoli G, Bartolucci M, Pistolesi M, Villari N, Mascalchi M. Chronic obstructive pulmonary disease: thin-section CT measurement of airway wall thickness and lung attenuation. Radiology 2005;234:604-610.

30. Berger P, Perot V, Desbarats P, Tunon-de-Lara JM, Marthan R, Laurent F. Airway wall thickness in cigarette smokers: quantitative thin-section CT assessment. Radiology 2005;235:1055-1064.

31. Hasegawa M, Onodera Y, Makita H, Nasuhara Y, Betsuyaku T, Nishimura M. Relationship between airflow limitation and airway luminal area measured by computed tomography imagings in chronic obstructive pulmonary disease [abstract]. Proc Am Thorac Soc 2005;2:A256.

32. Nakano Y, Whittall KP, Kalloger SE, Coxson HO, Flint J, Pare PD, English JC. Development and validation of human airway analysis algorithm using multidetector row CT. Proc SPIE 2002;4683:460-469.

33. The Committee of Pulmonary Physiology, Japanese Respiratory Society. Guidelines for Pulmonary Function Tests. Spirometry, flow-volume curve, diffusion capacity of the lung. Tokyo: The Japanese Respiratory Society; 2004 (in Japanese).

34. Burrows B, Kasik JE, Niden AH, Barclay WR. Clinical usefulness of the single-breath pulmonary diffusing capacity test. Am Rev Respir Dis 1961;84:789-806.

35. Nishida O, Sewake N, Kambe M, Okamoto T, Takano M, Aratani Y, Shigeto E, Sewake H, Nishimoto Y. Pulmonary function in healthy subjects and its prediction: 4 . subdivisions of lung volume in adults. Rinsho Byori 1976;24:837-841 (in Japanese).

36. Wood SA, Zerhouni EA, Hoford JD, Hoffman EA, Mitzner W. Measurement of three-dimensional lung tree structures by using computed tomography. J Appl Physiol 1995;79:1687-1697.

37. Ferretti GR, Vining DJ, Knoplioch J, Coulomb M. Tracheobronchial tree: three-dimensional spiral CT with bronchoscopic perspective. J Comput Assist Tomogr 1996;20:777-781.

38. Ferretti GR, Bricault I, Coulomb M. Virtual tools for imaging of the thorax. Eur Respir J 2001;18:381-392.

39. Matsuba K, Thurlbeck WM. The number and dimensions of small airways in emphysematous lungs. Am J Pathol 1972;67:265-275.

40. Bosken CH, Wiggs BR, Pare PD, Hogg JC. Small airway dimensions in smokers with obstruction to airflow. Am Rev Respir Dis 1990;142:563570.

41. Hogg JC. Pathophysiology of airflow limitation in chronic obstructive pulmonary disease. Lancet 2004;364:709-721.

42. Gurney JW, Jones KK, Robbins RA, Gossman GL, Nelson KJ, Daughton D, Spurzem JR, Rennard SI. Regional distribution of emphysema: correlation of high-resolution CT with pulmonary function tests in unselected smokers. Radiology 1992;183:457-463.

43. Matsuoka S, Kurihara Y, Nakajima Y, Niimi H, Ashida H, Kaneoya K. Serial change in airway lumen and wall thickness at thin-section CT in asymptomatic subjects. Radiology 2005;234:595-603.

44. King GG, Carroll JD, Muller NL, Whittall KP, Gao M, Nakano Y, Pare PD. Heterogeneity of narrowing in normal and asthmatic airways measured by HRCT. Eur Respir J 2004;24:211-218.

45. Kim SJ, Im JG, Kim IO, Cho ST, Cha SH, Park KS, Kim DY. Normal bronchial and pulmonary arterial diameters measured by thin section CT. J Comput Assist Tomogr 1995;19:365-369. 